\title{
Current Educational Issues in the Clinical Neurosciences
}

\author{
R. Desbiens, M.G. Elleker, G. Goldsand, H. Hugenholtz, D. Puddester, \\ B. Toyota, J. Max Findlay
}

\begin{abstract}
Objective: Canadian training in the clinical neurosciences, neurology and neurosurgery, faces significant challenges. New balances are being set by residents, their associations and the Royal College of Physicians and Surgeons of Canada between clinical service, education and personal time. The nature of hospital-provided medical service has changed significantly over the past decade, impacting importantly on resident training. Finally, future manpower needs are of concern, especially in the field of neurosurgery, where it appears that soon more specialists will be trained than can be absorbed into the Canadian health care system. Methods: A special symposium on current challenges in clinical neuroscience training was held at the Canadian Congress of Neurological Sciences in June 2000. Representatives from the Canadian Association of Interns and Residents, the Royal College of Physicians and Surgeons of Canada and English and French neurology and neurosurgery training programs made presentations, which are summarized in this report. Results: Residency training has become less service-oriented, and this trend will continue. In order to manage the increasingly sophisticated hospital services of neurology and neurosurgery, resident-alternatives in the form of physician "moonlighters" or more permanent hospital-based clinicians or "hospitalists" will be necessary in order to operate major neuroclinical units. Health authorities and hospitals will need to recognize and assume this responsibility. As clinical experience diminishes during residency training, inevitably so will the concept of the fully competent "generalist" at the end of specialty training. Additional subspecialty training is being increasingly sought by graduates, particularly in neurosurgery. Conclusions: Training in neurology and neurosurgery, as in all medical specialties, has changed significantly in recent years and continues to change. Programs and hospitals need to adapt to these changes in order to ensure the production of fully qualified specialists in neurology and neurosurgery and the provision of optimal care to patients in clinical teaching units.
\end{abstract}

RÉSUMÉ: Sujets d'actualité dans l'enseignement des neurosciences cliniques. But: La formation en neurosciences cliniques, en neurologie et en neurochirurgie fait face à des défis importants. Les résidents, leurs associations et le Collège Royal sont à mettre en place un nouvel équilibre entre le service clinique, l'éducation médicale et la vie personnelle. La nature du service médical fourni par l'hôpital a changé de façon importante pendant la dernière décennie, ce qui a eu un impact majeur sur la formation des résidents. Enfin, les besoins futurs en effectifs médicaux sont un sujet de préoccupation, spécialement dans le domaine de la neurochirurgie où il semble qu'on formera bientôt plus de spécialistes que le système de santé canadien n'en a besoin. Méthodes: Un symposium spécial sur les défis actuels dans la formation en neurosciences cliniques a été tenu au Congrès canadien des sciences neurologiques en juin 2000. Des représentants de l'Association canadienne des internes et résidents, du Collège royal des médecins et chirurgiens du Canada et des programmes de formation de langue anglaise et française en neurologie et en neurochirurgie ont fait des présentations dont le contenu est résumé dans ce rapport. Résultats: La formation au niveau de la résidence est moins orientée vers le service et cette tendance continuera. Dans la gestion des services hospitaliers de plus en plus sophistiqués en neurologie et en neurochirurgie, il sera nécessaire d'avoir recours à des substituts tels des médecins qui exercent ce travail médical en dehors des tâches exigées dans le cadre de la formation (moonlighting) ou des cliniciens hospitaliers plus permanents ou "hospitalistes" pour faire fonctionner les unités neurocliniques importantes. Les gestionnaires dans le domaine de la santé et les hôpitaux devront reconnaître et assumer cette responsabilité. À mesure que l'expérience clinique diminuera pendant la résidence, le concept du généraliste totalement compétent à la fin de la formation en spécialité s'estompera. Une formation en sous-spécialités additionnelles est de plus en plus courue par les gradués, particulièrement en neurochirurgie. Conclusions: La formation en neurologie et en neurochirurgie, comme dans toutes les spécialités médicales, a changé de façon importante dans les dernières années et continue de changer. Les programmes et les hôpitaux doivent s'adapter à ces changements afin d'assurer la formation de spécialistes pleinement qualifiés en neurologie et en neurochirurgie et le traitement optimal des patients dans les unités d'enseignement clinique.

Can. J. Neurol. Sci. 2001; 28: 283-292

This article is based upon a series of presentations given on the topic of training in the fields of neurology and neurosurgery, which, along with an audience-panel discussion comprised a special symposium of the Canadian Congress of Neurological Sciences in Ottawa, June 2000. The symposium was organized in response to what is considered a difficult and perhaps even critical time in the history of clinical neuroscience training in
From Laval University, Quebec, QC (RD), University of Alberta, Edmonton, AB, (MGE, GG, JMF), Dalhousie University, Halifax, NS (HH), Children's Hospital of Eastern Ontario, ON (DP), University of British Columbia, Vancouver, BC (BT) Canada

Received January 18, 2001. Accepted infinalform August 18, 2001. Reprint requests to: J. Max Findlay, Division of Neurosurgery, 2D1.02 W.C. Mackenize Health Sciences Centre, 8440 - 112 Street, Edmonton, AB T6G 2B7, Canada 
Canada, and was attended by representatives of the Royal College of Physicians and Surgeons of Canada (RCPSC), department chairmen, training program directors, academic and clinical faculty, and trainees from across the country.

What makes training in neurology and neurosurgery any different now than in times past? As expressed by each presenter, it is harder now than ever before to meet the educational and personal needs of trainees, which have in part been defined in educational standards set by the RCPSC and agreements on working conditions between resident associations and governments, and at the same time meet the increasingly sophisticated medical service demands - traditionally provided by residents - of hospitals and clinical units used as training grounds for these same trainees.

There are a number of practical and emotional issues involved in this discussion. As Dr. Goldsand outlines, training programs require RCPSC certification, for which evidence of regular training committee meetings, properly documented and meaningful resident and teacher evaluations, structured teaching sessions, protected academic or study time, and journal clubs must be provided. This considerable task demands unprecedented diligence and commitment on the part of program directors and training committees. Physician-patient communication skills, medical ethics and medical-legal matters, subjects of great importance, are more difficult to teach formally and regularly, and perhaps even harder to document as being taught at the time of program review. Do these changes mark the end of the apprenticeship model of training? Not at least for the more manual task of neurosurgery, argues Dr. Toyota in his provocative contribution.

Similarly, ensuring that residents do not have to take hospital call more than one night in three (or one in four, as is now the case in Ontario, or soon even one in five, as predicted by Dr. Puddester), or remain in hospital providing clinical service any longer than 25 consecutive hours (as is the case in Alberta) seems desirable and conducive to a satisfactory resident life-style. These rules, however, unavoidably reduce clinical experience and learning. This is the case especially for senior and final year neurosurgery residents, as emergency surgery is an important part of neurosurgical practice. Will our trainees have seen everything and done everything, in a position of responsibility, by the time they begin their own practice? It is unlikely that training periods will be extended in order to compensate for new call-schedule rules.

In addition, there is the more practical problem of simply filling hospital call schedules under these new rules, which has sent programs scrambling for some kind of "resident alternative" to take call for clinics and wards. Only Ontario forbids its residents from "moonlighting" for cash. Quebec residents are not allowed to be remunerated for call-coverage in a hospital where they themselves are training at the time. Some of us have been in the awkward situation of hiring each other's residents to fill gaps on our services when residents are "off-call" on their own, as described by Dr. Elleker. Resident associations have recognized the irony of this situation and its inconsistency with their agreements with government restricting resident call but make the valid argument that capable residents, with their extraordinary and under-valued skill-set, should be entitled to profit from the system as they see fit. Who among us doesn't remember the burden of student loans? Other programs, including the neurosurgical program at the University of Alberta, have taken the route of hiring and training international medical graduates as hospitalists, able to take first night call exactly like a resident, and working with the residents during the day.

There are problems that "modern" health care has created for specialty training, outlined by Drs. Elleker, Toyota and Desbiens. Within the last decade, hospital admission for medical stabilization or improvement of chronic neurodegenerative or demyelinating conditions has become uncommon, and admission before the day of elective surgery for even major neurosurgical disorders is a luxury of the past, so resident exposure to these patients and their problems is limited. Chief residents in neurosurgery, busy, as they need to be in operating rooms every day, are left with no way of properly interviewing and examining many, if not most, of the patients they will learn their surgical skills on and, with shortened hospital stays, have little exposure to them afterwards. Treatment decision-making, preparation and postsurgical care are important education challenges for neurosurgical training programs.

Manpower is another problem, at least for Neurosurgery. Following a 1998 decision of the American Board of Neurological Surgeons graduates of Canadian neurosurgical training programs after 2002 are no longer eligible to write and sit the American Board examinations in neurosurgery in order to be "board-eligible" for practice in the USA. Can all of our neurosurgery graduates find employment in Canada, when up until now roughly one-half of our new graduates have emigrated south? Our residency programs and teaching hospitals have, up until now, needed a critical number of residents to sustain our programs but, as Dr. Hugenholtz demonstrates in his important study summarized in this article, in a very short while we won't need the number of neurosurgeons we are producing. Fortunately this problem with board eligibility has not arisen in neurology and, at present the only manpower issue in Canada is a relative shortage of neurologists in certain parts of the country.

\section{Resident Associations and Training: Past, Present, and FUTURE}

\section{Puddester - Past President, Canadian Association of Interns and Residents, Psychiatrist, Children's Hospital of Eastern Ontario}

Canada has a medical resident education and training system that is admired around the world. This training system comprises multiple stakeholders with differing values, beliefs, and ideologies. Yet, it manages to move forward and our collective output - Canadian physicians - are well-regarded, valued and highly trained.

Historically, Canadian residents were among the first in the world to develop their own organized bodies to advocate and bargain on their behalf. They have brought about a significant revision of their work environment, and an increased involvement in the institutions and associations that direct their education and licensure. Originally "housestaff" referred to physicians who were on call - sometimes on a 1:1 roster. For this service, residents received a small stipend and there was no concept of separate educational time as we know it today. In this 
milieu, residents organized themselves into "Professional Housestaff Associations" (PHOs) on a provincial basis, and began to collectively bargain on behalf of their members. Early results included a limitation of call to $1: 3$, improved pay and recognition that residents were both providers of service and postgraduate learners. Another early success was the understanding that residents would provide clinical education to medical students in exchange for an elimination of their own university tuition fees.

The work environment as it relates to the provision of on-call services has improved further. PHOs have recently negotiated a frequency of call no greater than 1:4, specified when residents must be relieved of duty post-call, and have developed standards of call room quality, security and access. Vacation, educational and statutory holiday leaves have been defined, and continue to evolve. Parental leaves are also being clarified across Canada, with some provinces having negotiated leave for both mothers and fathers. Future issues in contract negotiations will likely involve debates on tuition for residency education, movement towards a 1:5 call frequency, absolute working hours for trainees and policies to manage intimidation and harassment complaints.

Residents recognized that many educational issues were national ones, so the PHOs formed the Canadian Association of Interns and Residents (CAIR). This body has identified a number of core educational issues, including the balance of education and service, valid and reliable evaluation and appeals processes, protected educational time, need for conference and examination leave, the need to participate in national educational bodies such as the RCPSC, the Canadian College of Family Practice (CCFP), and the Medical Council of Canada (MCC).

The health and well-being of physicians is a growing and important theme in medical training. In 1997, CAIR developed and released a position paper on this subject complementing similar efforts made by the Canadian Federation of Medical Students and the Canadian Medical Association (CMA). This policy area has led to the formation of new national organizations (the Canadian Forum on Physician Health and Well-Being) which are developing strategies to help physicians stay healthy for themselves, their families, and patients. Undergraduate programs are being urged to develop curricula on mental illness, substance use and stress. Postgraduate programs are being called upon to develop standards on access to physician health programs and curricula. Faculties of Medicine are developing "zero tolerance" policies on intimidation and harassment. The CMA Women's Issues Committee has developed a report that can help our profession adapt to an evergrowing number of female physicians. Complementing the report are calls from Residents Associations for supported parental leave, part time residencies, and access to day-care.

Another issue relates to the challenge of helping residents who are unhappy in their career choice and wish to change into another training program. CAIR completed a survey on program switching which indicated $25 \%$ of residents considered switching, 4\% had already switched, $8 \%$ tried to switch and failed, and only $63 \%$ were not at all interested in switching. Residents indicated their reasons for considering switching as their being unhappy with their chosen specialty, excessive workload, changing career opportunities after certification, intimidation, program location, and remuneration. Twenty- seven percent of respondents indicated their choice would have been different if made later in training and $50 \%$ felt they could never change, even if they wished to. Barriers to switching included a perception there was no spot to change to $(75 \%)$, lack of knowledge on how to change $(56 \%)$, fear of losing credit for training already completed $(53 \%)$, and fear of intimidation or reprisal if switching was attempted (46\%). These findings have been presented to the Canadian Medical Forum, and each province is trying to develop strategies to facilitate program switching.

There are many other issues facing our training and education system. Provincial physician resource issues continue to be a great concern, and residents have made contributions towards a solution such as the formation of the CAIR Secretariat on Physician Resources. Managing trainees with blood borne illnesses (such as HIV and hepatitis) is complex but residents have helped hospitals and universities develop fair policies. Training evaluation processes suffer from subjectivity and inadequate standardization so resident representatives have worked with both the RCPSC and the CCFP to improve them. Training programs are struggling to manage their educational responsibilities as their clinical demands grow and resources shrink, and again residents at local, provincial, and national levels have been working to develop creative but fair solutions to these challenges.

Canada is felt to have one of the best education and training systems in the world, and Residency Associations have been one player in the evolution of this system. Residents are prepared to tackle the complex issues we now face. Given their comfort in thinking "outside the box," the future of our educational system looks very bright indeed.

\section{Resident Training Program Evaluation: What Are the Hallmarks of an Excellent Program?}

\section{G. Goldsand - Former Associate Dean, Postgraduate Medical Education and Presently, Advisor to the Dean on Educational Issues, University of Alberta}

Over the past several decades the training of specialists has evolved from a purely apprenticeship experience to one comprising structured, objective-based programs that operate in accordance with constantly developing guidelines established by a central national authority, the RCPSC, and subject to a careful and regular accreditation process. In all instances, a Specialty Committee comprised of specialists from that discipline determines the specific guidelines. Controversy regarding failure of some programs to achieve full accreditation status is often based on a failure to fully understand the criteria on which such decisions are made. In addition, some specialty administrators may not fully appreciate some of the educational reforms that have evolved over the past several years. These include:

1) Protected time for academic, educational and dedicated research activities;

2) An increased segment of training in an ambulatory care setting;

3) The establishment and legislation of more "humane" working hours and a more respectful and less intimidating environment for residents; and 
4) The establishment of certain generic skills and attitudes within the formal curricula of training programs (often referred to as the CanMEDS 2000 competencies by the RCPSC).

The accreditation process is based on compliance with welldocumented standards. These are broadly categorized into socalled "A" standards that deal with the general administration and infrastructure within the Faculty of Medicine and teaching hospitals and "B" standards that deal with each individual program. The six "B" standards (Table 1), each of which have many subcategories, address the program components and serve as the basis for accreditation of programs as they are surveyed by the RCPSC at least once every six years.

Table 1: "B" Standards for Residency Program Accreditation, Royal College of Physicians and Surgeons of Canada
B.I Administrative Structure
B.II Goals and Objectives
B.III Content and Organization
B.IV Resources
B.V Academic and Scholarly Aspects
B.VI Evaluation of Resident Performance

The vast majority of programs in Canada are judged very favorably in relation to standards B.IV and B.V. The abundant patient and facility resources and strong academic component of the programs has produced highly competent specialists. The difficulties encountered by some programs at accreditation have tended to be due to problems in the other standards. Examples in each of these are cited below.

\section{B.I Administrative Structure}

Far too often, the Program Director operates as a "one-person show" with the role and composition of the full Residency Program Committee (RPC) poorly defined. It is important to clearly define the role and reporting lines of individual members of the RPC, ensure that the content of meetings includes regular and careful review of the training requirements and accreditation guidelines, all of which are clearly published and widely available. It is important that the RPC meet regularly in order to ensure that educational issues are the principal reason for meeting, and not added to full agendae of separately scheduled departmental or divisional meetings that are dominated by noneducational issues. It is also essential that residents have meaningful input into the discussions of the RPCs. There is a tendency for small programs to assume no need for more formal discussions because they "communicate every day" with the housestaff. This is recognized as a sign of a program in potential difficulty.

\section{B.III Content and Organization}

There are several components to this standard, most of which are generally not problematic. The one that seems to create difficulty, especially in certain surgical programs, is Standard B.III.4, that states "service demands must not interfere with the ability of the resident to follow the academic program". The failure of these programs to maintain an appropriate service/education ratio has recently led to a provisional approval status for several programs at accreditation.

\section{B.II Goals and Objectives and B.VI Evaluation of Resident Performance}

These are discussed together because of the failure of many programs to base the resident evaluation process on previously established general and rotation-specific objectives. The evaluation process must include both end of rotation evaluations by the relevant preceptor(s) and regular summative evaluations that are the responsibility of the Program Director. The former must be timely, comprehensive and based on rotation-specific objectives which must be widely circulated and have been read before the rotation by both the resident and all members of the supervising faculty. Summative evaluations by the Program Director should occur with each resident at least twice yearly and must also include an opportunity for feedback from individual residents about general and specific aspects of their training programs, and to review relevant personal, family and career issues. Sufficient frequency and appropriate content of such meetings will help to build a better climate of trust and collegiality, and enable Program Directors to clearly establish themselves as resident advocates. In too many situations this dialogue tends to occur informally and irregularly. This may result in failure to address various academic problems in a timely fashion and may also lead to some reluctance for some residents to bring a variety of personal problems or concerns to the attention of the Program Director.

\section{Formal dialogue between resident and Program Director}

While residents have sought such feedback for many years, it is only recently that Program Directors have started to deal with this in a more sustained manner. One of the important stimuli for this was the recent introduction by the RCPSC of a Confirmation of Completion of Training (CCT) Form for each resident as part of their application process for examination. The key paragraph of this brief form reads as follows:

"This will attest that the applicant(s) listed below has/have or, by the end of the training date shown, will have satisfactorily completed the minimum training required for the Royal College examinations in the specialty shown above and has/will have attained knowledge, skills, attitudes and judgment necessary for the independent consultant practice of the specialty, as determined by the in-training evaluation system of the residency program. This will further attest to the satisfactory moral and ethical standing of the applicant(s)."

As the CCTform must be signed for each resident by both the Program Director and Post Graduate Medical Education (PGME) Dean, an awareness has developed about the need for a more serious evaluation system for individual programs and careful monitoring of this process by the office of the PGME Dean. In some programs reluctance by a Program Director to affix their signature to such a statement highlighted a failure by the program to have effectively addressed problems at an earlier stage of training, specifically revealing a deficiency in the 
evaluation, feedback and remedial system within the program. At the University of Alberta, we attempted to facilitate this issue by developing a requirement for all Program Directors to complete a six-monthly evaluation report for each of their residents and submit this to the PGME Dean's office. The intent was for this concise form to be used by the Program Director at a formal scheduled meeting with each of their residents at least twice per year and more often with any residents having some difficulty. Preparation for such meetings should include completion of this form to serve as a basis for doing the summative evaluation. The form should contain a cumulative summary of each of the residents' completed end-of-rotation evaluations, with breakdown into knowledge, skills and attitude components. (This process would also ensure that each end-of-rotation evaluation has been completed, reviewed with the resident and returned to the Program Office). Traditionally, evaluations have focused primarily on knowledge and skills. It is important that the "attitude" component also be addressed, recorded, counselled and remediated if there are problems. There is provision for the form to be signed by the resident and Program Director. The report would also contain a space for clearly attesting that the resident has successfully completed the objectives of that year and can comfortably progress to the next level of training.

The "attitudes" component of evaluation might be guided by the resident's mastery of the CanMEDS 2000 competencies that programs are now expected to teach, role-model and evaluate. These are Medical Expert, Communicator, Scholar, Collaborator, Manager, Professional and Health Advocate. Training programs have traditionally excelled in the Medical Expert competency. The remaining six represent a more challenging dimension for many programs. There is considerable variation among individual programs across Canada in addressing these competencies within their curricula. It is recognized that eventual success will require faculty development to occur concurrently with establishment of academic programs for residents.

\section{The hallmarks of an "excellent" program}

It is acknowledged that Canadian programs have and continue to produce highly skilled specialists. In addition to continuing this tradition, programs should also strive for:

1) A functional and effective RPC with meaningful resident participation;

2) Constant review by the RPC of accreditation guidelines;

3) An objective-based evaluation system;

4) Faculty development to enable role-modeling of CanMEDS 2000 competencies; and

5) Enhancing/developing a culture of trust and mutual respect between faculty and residents.

Changing Paradigm in Neurology Resident Training: the University of Alberta Experience

\section{M.G. Elleker - Resident Program Director, Division of Neurology, University of Alberta}

\begin{abstract}
"Change is not made without inconvenience, even from worse to better." - Samuel Johnson
\end{abstract}

The acute care hospital-based service-for-education paradigm is breaking down. There is an increasing need to ensure the validity of training experiences as models of actual clinical practice which, for the specialty of neurology, has become largely community- and ambulatory-based. At the same time, however, the demand for inpatient care by specialist teachers is undiminished. Along with an increase in average inpatient illness acuity, there is a constant drive to reduce hospital lengths-of-stay. These are stressful times for patients and clinicians alike.

These changes have affected Neurology training programs variably across Canada, depending upon factors such as the regionalization of services, the local roles of internists and family physicians in the care of neurological inpatients who have significant medical comorbidities, the penetration of new approaches to acute stroke management (such as thrombolysis and the introduction of the stroke units), and the size of training programs (i.e. resident numbers) in relation to service demand. In many places, these changes have led to service/education mismatches. These mismatches impact students and residents directly, and also their teachers, profoundly. A simple shift of service demand onto the workload of teachers serves resident education poorly.

The experience of the Neurology training program at the University of Alberta in Edmonton is illustrative. Edmonton is the neurological referral centre for a population of approximately 1.6 million in northern Alberta and contiguous areas of British Columbia, the Northwest Territories and Saskatchewan. All 17 neurologists (12 in clinical full-time practice) in the region are teachers in the Neurology resident training program. Regionalization of inpatient services to a single hospital occurred in 1995. The Regional Health Authority is said to be the largest in the country. At about the same time as regionalization, there was an early focus on acute stroke management leading to the creation of a regional stroke unit. The result was a dramatic increase in service demand at one site where neurological inpatient care was concentrated. There were approximately 1,500 admissions per year at the central site. About three-quarters of admissions were strokes. In addition, there were approximately 2,100 inpatient and Emergency Department consultations per year at the primary site and an additional 1,600 consultations at three other hospitals. At the primary site, there was no Family Medicine presence and the General Internal Medicine program, at the time similarly pressured by service demands, became unable to admit neurology patients. The Neurology Residency Training Program consisted of five or six residents, with a variable number of secondments from related training programs.

Within two years it was apparent to the RPC that the existing service model was not serving the training needs of Neurology residents. There was an excessive focus on acute stroke management, insufficient ambulatory care experience, and a deteriorating in-hospital consultation experience, all due to the demands of primary care for stroke patients and the need to attend to patients in the Emergency Department. There was insufficient time for elective experiences or research.

The attention of the Regional Health Authority was finally caught when the RPC, with the support of the Divisional Director, deliberately provoked a crisis. Resident assignments were made primarily on the basis of educational objectives, leaving significant gaps in the schedule for inpatient coverage, including nights and weekends. Residency Program Committee 
members recognized that the initial burden of filling these gaps would fall on their shoulders and those of the other teachers. The committee recognized that they, the teachers, had no resources with which to solve the problems they had created.

The crisis led to three outcomes. Firstly, a hospitalist with Internal Medicine background was recruited to assume responsibility for the care of stroke patients, many of whom had medical comorbidities. Secondly, "resident alternatives" were recruited for night and weekend first-call coverage. These were residents "moonlighting" from other training programs where the inpatient service demand was either less or unevenly distributed across years of training. There was no other available pool of medical providers with the appropriate skill sets that could be identified at the time. Moonlighting residents provided an average of seven shifts per month. Thirdly, the attending neurologists took a more active role as "first call" providers during daytime hours, resulting in obvious limitations on clinic, office and academic time when they were "on-call".

These strategies required the active support of the Regional Health Authority and the College of Physicians and Surgeons of Alberta. The Regional Health Authority provided an income guarantee for the hospitalist and remuneration for moonlighters. The Provincial College allowed special licensure for moonlighting residents, with restrictions regarding the number of hours allowed and monitoring of the impact of moonlighting on the performance of residents in their home training programs. These strategies have now been employed in other clinical programs in our region with high acuity inpatient loads (Orthopedics, Internal Medicine, and Critical Care) and the monitoring process around moonlighting has successfully met review by the Alberta Provincial College in April 2000.

The hospitalist strategy is well-developed in several jurisdictions, especially in the United States where specific training programs and certification processes for hospitalists are being developed. There are significant issues around remuneration, given that most provincial fee schedules grossly inadequately reimburse the care of high acuity inpatients outside ICU settings. Fee-for-service billings relating to the care of such patients are insufficient to attract capable physicians into the hospitalists'role unless income is supported from other sources.

While working at present, the moonlighting resident strategy is problematic. The opportunity to work large numbers of shifts might lead some residents to compromise their own residency training experience. This concern led the Provincial College of Alberta to establish conditions on Special Licensure for moonlighters, including formal approval by the resident's Program Director, strict workload limitation, and mechanisms to ensure that skill sets are appropriate. The moonlighting resident works in a supervised setting where issues of liability and responsibility of the attending physician of record are clear. There has been some resentment among residents who are not permitted to moonlight because they are in programs with high call frequency. Other residents may be "advantaged" if they are in programs with low call frequency or if they are in programs where inpatient hospital call responsibilities are minor. Residents in the latter situation are better able to supplement their incomes by working as moonlighters. The moonlighting resident strategy is likely to continue, as long as there are no alternative care providers with appropriate skill sets.

\section{Challenges in Post-Graduate Neurosurgical Education}

\section{B. Toyota - Resident Program Director, Division of Neurosurgery, University of British Columbia}

Neurosurgical training has traditionally used apprenticeship as the fundamental model to transform residents into surgeons. This apprenticeship involves the triad of surgeon, resident, and patient, each with specific expectations and responsibilities to the other. A successful training program must establish a delicate and precise balance between each member of the triad to ensure optimal patient care, sound resident education and surgeon satisfaction. Current medical, political, social and educational trends challenge this triad. A response is necessary to maintain Canadian neurosurgical training at the level we have come to expect. This section highlights four major challenges, describes how they impact neurosurgical training and the apprenticeship model in particular, and offers some suggestions on how they can be met.

\section{Service-to-education balance}

In the apprenticeship model the trainee gradually assumes greater responsibility for the care of neurosurgical patients. Along with that responsibility comes a wide range of duties and services that constitute complete patient care. Some aspects of this care are unglamourous, repetitious and not strictly "educational", but they are fundamental parts of the neurosurgeon's work. In this context it is not surprising that issues regarding "service work" versus education arise. To properly meet this challenge trainees must understand that we need to teach, not only the facts of neurosurgery, but also the practice of neurosurgery.

In this paradigm all patient care services performed by the resident are assimilations of the duties of the surgeon, and in that sense are educational. If patient care is a continuum of obligations, then arranging home-care is no less educational than performing an operation. The general education of the neurosurgical resident cannot be easily partitioned because patient care is a continuum. Residents cannot simply drop in and out of a given patient's care.

Interestingly, CanMEDS 2000 objectives have blurred the line between service and education. These objectives have expanded what a residency program can legitimately call education as opposed to service work. For example, a discharge summary becomes a work of collaboration, administration and communication, and even a forum for health advocacy!

On the other hand, perfunctory duties that provide service only to the hospital should be removed from the residency. Excessive and exhausting on-call duty only provides service to the hospital. To help avoid "service-to-education" issues, it is suggested that academic clinical services be capable of operating effectively without housestaff, as frightening as that prospect sounds. If quality patient care can be provided by consultants and other clinicians, including perhaps hospitalists alone, there will never be an undercurrent of obligation imposed on residents. The quality of patient care is the responsibility of the consultant and the hospital, with or without the residency program.

\section{Neurosurgical subspecialization}

Modern neurosurgery is becoming increasingly subspecialized, and this has had some deleterious effects on 
neurosurgical residency. Progressive, graded responsibility and surgical experience as the senior resident have been undermined by subspecialization. Instead of a continuous flow of mixed patient problems, residents face a series of subspecialty rotations such as spine, vascular neurosurgery and pediatrics. The experience of certain subspecialties has become more "exposure and familiarity" than acquired competence. The general technical expertise of the residents is diminishing as more fields within neurosurgery attain sovereign existence.

The solution to subspecialization is not clear. Alternatives include extending neurosurgical training or considering fellowship training a necessity for certification. Ironically, certain fellowships further antagonize the general education of program residents, creating competition for the limited amount of subspecialty instruction. The general skills of a neurosurgeon are enormously enhanced by the accumulation of as many skill sets as possible.

\section{Resources to support training}

The combination of diminishing resources and increased training requirements is another challenge. Despite being under University governance, neurosurgical residency programs exist within major urban hospitals. As hospitals in Canada struggle to function with evaporating resources, the priority of education drops. The "same-day admission" concept is an example. Whereas same-day admissions clearly decrease hospital costs, they remove a crucial component of surgical education. No reliable system compensates for the lost opportunity for residents to make pre-operative assessments and contact with the patients upon whom they will operate.

Depleted health care budgets, increasing amounts of time required for patient administration and dwindling financial rewards directly affect the ability of clinicians to serve as instructors for their apprentice. In many ways, the lack of resources hinders the sincere desire of surgeons to teach, maintain efficient patient care and earn a living. Curtailing resident operating experience so as to more efficiently use operating room time is just one example of a lack of health care dollars directly harming postgraduate education.

\section{Establishing and evaluating valid training requirements}

The primary objective of neurosurgical training is the production of a surgeon who is "competent to function as a consultant in neurosurgery". Such an expertise is best achieved by the neurosurgeon serving as a role-model. In this way, all the elements necessary to practice neurosurgery are passed on. This includes the knowledge base and technical skills of the specialty, as well as the demeanor and comportment of a neurosurgeon. The apprenticeship model teaches behavior as well as knowledge.

The RCPSC objectives of training, and specifically those of CanMEDs 2000, are valid. Difficulties arise in determining that they have been taught. The standard methods of examination can adequately test a knowledge base but are less applicable to behavior. So how does an accreditation body ensure that they are being achieved? Is it the job of the Program Director to prove it or the Surveyor's job to detect it? The onus has been placed on training programs to document a transparent curriculum that would verify that these "non-testable" behaviors have been taught. This stance implies that such behaviors have not been taught if teaching cannot be documented. However, the apprenticeship model sufficiently ensures that graduates achieve the essential ingredients of ethics, health-advocacy and communication. The apprenticeship method teaches behavioral attributes in very direct and personal ways.

Methods should be developed to determine competency in regard to these behavioral attributes. How behaviors are transmitted by the apprenticeship model is proposed as a subject for educational research.

Acknowledgement: The author thanks Dr. Barry Woodhurst for his help in preparing these comments.

\section{Service to Education Balance in the French Neurology Training Programs}

\section{R. Desbiens - Neurology Program Director, Laval University}

There are three French neurology teaching programs in Canada and all are in the province of Quebec: the Universities of Sherbrooke, Montreal and Laval in Quebec City. Each program takes two new residents every year. At this moment, twenty-eight residents are training in these programs.

Is there anything that distinguishes these programs from other neurology programs elsewhere is Canada? Until recently, one difference in the Quebec programs was the amount of time spent in electrophysiology training, which was much longer than elsewhere in Canada. Most, if not all, residents chose to spend a full year in electrophysiology (EMG, EEG and evoked potentials). This situation created problems with the RCPSC who considered this exposure excessive. The main reason for the emphasis on electrophysiology in Quebec was related to our provincial requirements. Until this year, an EEG certificate was needed to interpret and bill for EEGs in Quebec, and the minimum requirement for this certificate was 12 months of training in electrophysiology including at least six months of EEG. This certificate was abolished in 2000 and this change has allowed program directors to adjust the contents of the programs to meet all the requirements of the RCPSC.

The three French neurology programs do not participate in the CaRMs program and recruit residents based on individual applications to each program. Every program has structured interviews, a system still possible given the small number of applicants and the geographic proximity of the three sites.

All three French neurology programs function in a "cocoon" model with most of the teaching at one site, along with the teaching units, research, specialized clinics, neurosurgery, neuroophthalmology, and neuro-otology. Advantages of this system are that teaching rounds, journal clubs, basic science lectures and neuropathology can be done at one site and integrated in a daily schedule without difficulty. Also, the concentration of resources allows interaction between residents whose on-call duties are less frequent. No gaps occur in the resident call rosters. In Quebec, residents are not allowed to "moonlight", which perhaps avoids the related problems that occur in other provinces.

\section{Problems and solutions}

The most common complaint from residents in Quebec is the excessive number of patients on the teaching units. Residents 
also complain of clustering and poor timing of admissions either late in the day or during rounds. The argument that this variability is an intrinsic component of medicine has been rejected by the RCPSC reviewers. They have insisted that teaching units be protected in terms of not only the number of patients they accept, but also the type (ie. consisting mostly of "active" patients with dissimilar pathologies).

Teaching staff have had to take charge of new patients rapidly for both medical and legal reasons and because of pressure to shorten hospital stays. The distribution of residents also creates problems, with excessive numbers during certain months and very few during others. Off-duty days post-call create a lack of continuity in the care of patients and sometimes a burden on residents remaining on-duty.

We have found that a fixed and limited number of patients should be maintained in the teaching unit, with overflow beds available outside of the teaching unit where residents are not required for the care of those patients. The staff neurologist should be able to adapt to the needs of his or her team of residents.

\section{Manpower}

We expect an increase in the number of neurologists needed in Quebec in the next decade. Aging of the population and emergence of new therapies such as thrombolysis will create manpower demands in our field. Fifty percent of the 160 neurologists in the province are above age 55 and will likely retire in ten years. The number of neurologists produced by our programs (including McGill University) is generally adequate.

\section{Conclusions}

Teaching neurology to residents is more challenging than ever before. Transformations in the health care system, new guidelines set by the national and provincial colleges, and increasing demands from neurology residents in terms of quality of life and abundance of teaching, create challenges. Program directors and teachers often feel that they already provide a good learning environment. Requests for change are perhaps best taken as opportunites to improve programs that are already good. Adaptability is the key word, and it is a must to survive in the medical teaching world.

Acknowledgement: The author thanks Drs Hélène Masson and Samir Jarjoura (respectively Neurology Program Directors at University of Montreal and University of Sherbrooke) for their help in preparing these comments.

\section{The Canadian Neurosurgery Workforce and Training Capacity ON July 1, 2000}

\section{H. Hugenholtz - Division of Neurosurgery, Dalhousie University}

A review of the Canadian neurosurgery workforce during the spring of 2000 suggests a current excess capacity in our training programs. This is in striking contrast with concern about a potential shortage of neurosurgeons and trainees following a similar review in $1995 .{ }^{\circ}$ As a result of restrictions on the certification of foreign-trained neurosurgeons imposed by the
American Board of Neurological Surgery (ABNS), current PGY1 to PGY-3 trainees in Canadian neurosurgery training programs are no longer eligible for board certification, forcing them to rely on Canada and possibly other jurisdictions for employment. Established neurosurgeons are no longer emigrating and retiring from their Canadian practices at the traditional rate of the late 1980 s and early 1990s. Restructuring has increasingly centralized the resources for neurosurgical practice and reduced the number of potential new positions. Despite a decline in the number of applicants for neurosurgery training in recent years, our current training capacity exceeds the number of projected vacancies unless the ABNS repeals its current intent to restrict board eligibility to our trainees and patterns of retirement and emigration were to revert to traditional numbers.

\section{Methods}

Names of all neurosurgeons engaged in active clinical practice in Canada were obtained by telephone from colleagues in each city. Questionnaires addressing demographics, practice profile and age of retirement were then sent to each practicing neurosurgeon. Outstanding and incomplete responses were tracked by direct telephone contact. Lists of trainees and their level of training were obtained from each training program director. Lists of successful certificants by year were obtained from the RCPSC and the location of practice of each was obtained from directories and by telephone confirmation. All responses were tabled by region and by category.

\section{Results and discussion}

One hundred and sixty-eight of 180 responded to all questions.

\section{Workforce demographics - July 1, 2000}

The total of 180 practicing neurosurgeons, as of July 1, 2000, including nine women, reflect a net gain of six from January 1, 1996 but still falls short of the 228 recommended by the RCPSC in $1988 .{ }^{2}$ The age distribution by region reveals a preponderance of senior neurosurgeons (age $>55 \mathrm{yrs}$ ) in the Maritimes and the western provinces (Alberta and British Columbia) and a preponderance of younger neurosurgeons (age <46 yrs) in Quebec, Manitoba and Saskatchewan. There has been an increase in the proportion of neurosurgeons who devote $50 \%$ or more of their time to a subspecialty. Forty-three percent of respondents continue to practice as financially independent feefor-service practitioners while the remainder share some expense and/or income from fee-for-service, salaries or combinations thereof.

\section{Trainee demographics - July 1, 2000}

Table 2 depicts the distribution of trainees by region and the ratio of trainees per practicing neurosurgeon by region. On July 1, 2000 there were 100 trainees from PGY-1 to PGY-6 eligible for a Canadian licence. There were also three eligible fellows. Twenty percent of the eligible trainees were women. The majority of eligible trainees are concentrated in programs in Ontario and Quebec. There was a disproportionate number of trainees at the PGY-5 level, who will become eligible for certification by the year 2002. There was a high ratio of trainees to practicing neurosurgeons in programs in Ontario, Quebec and the Prairie provinces. The majority of trainees remained in the 
region where they trained. The exceptions were the three programs in B.C. and Alberta, who exported up to $40 \%$ of their trainees to other Canadian jurisdictions. The proportion of graduates emigrating to jurisdictions outside Canada within two years of certification has not changed from the traditional exodus of $50 \%$ (See Table 3).

\section{Exit from the Canadian neurosurgery workforce - January 1, 1996 to July 1, 2000}

Thirty-eight neurosurgeons stopped active clinical practice during this interval. Fourteen relocated to a jurisdiction outside Canada and the remainder retired due to age, health or career change. In addition, four neurosurgeons relocated to other jurisdictions within Canada. Twenty-eight percent of retirees were under age 65 . The median age of retirement was 67 . Only two centres had firm policies regarding mandatory retirement after age 65 .

\section{Entry into the Canadian neurosurgery workforce - January \\ 1, 1996 to July 1, 2000}

Table 4 depicts recruitment by region between January 1, 1996 and July 1, 2000. Quebec now has the most youthful profile of neurosurgeons in Canada. Manitoba and Saskatchewan have had to resort to recruiting international medical graduates (IMGs). On July 1, 2000, there were 12 available positions in Canada for eligible certified neurosurgeons.

\section{Evolution of the Canadian neurosurgery workforce after year 2000}

Restructuring has centralized the resources for neurosurgical practice and reduced the number of new positions except for replacements for those retiring from active practice. The ideal of minimum numbers of neurosurgeons in academic centres and in other communities to fulfill the academic mission and to provide quality care through interaction with peers has been threatened by centralized resources through restructuring. ${ }^{1}$ Unless individual groups are able to negotiate additional resources for new positions, the capacity of the workforce is not likely to change significantly. The four years from 1996 to 2000 were characterized by a reduction in the exit rate of neurosurgeons from the traditional pre-1996 rate of 12.5 per year (five from age/health and 7.5 from emigration and other) to 8.5 per year (4.5 from age/health and four from emigration and other). The feminization of neurosurgery may further affect resource utilization and exit rates in the future. It appears to have had an impact on family medicine. ${ }^{3}$ As a result of restricted access by IMGs to our training programs, there has been an increase in the number of potential eligible graduates. The number will increase exponentially after the current PGY-4 trainees complete their training and find themselves no longer ABNS-eligible, forcing them to look in Canada and other off-shore jurisdictions for work.

Table 5 considers current trends in exit and entry. Assuming that our current PGY-4,5 and 6 trainees who are still ABNSeligible continue to exit to the US at a rate of $50 \%$, and that those choosing to stay in Canada will match the specific criteria of the available positions, then we could begin to experience a surplus of graduates from our training programs by as early as the year 2004 and certainly thereafter. Alternatively if more than 50\% of our current trainees who remain ABNS-eligible decide to stay in
Table 2: Distribution of eligible trainees and proportion of eligible trainees per practicing neurosurgeon by region on July 1 , 2000

\begin{tabular}{|c|c|c|c|c|c|c|}
\hline & Canada & Maritimes & Quebec & Ontario & Manitoba & Alberta \\
\hline & & & & & SK & $\mathrm{BC}$ \\
\hline PGY-1 & 16 & 1 & 5 & 6 & 2 & 2 \\
\hline PGY-2 & 17 & 1 & 8 & 4 & 2 & 2 \\
\hline PGY-3 & 16 & & 7 & 6 & 2 & 1 \\
\hline PGY-4 & 16 & 1 & 6 & 7 & & 2 \\
\hline PGY-5 & 24 & 1 & 7 & 13 & & 3 \\
\hline PGY-6 & 11 & 1 & 3 & 4 & 1 & 2 \\
\hline \multicolumn{7}{|c|}{$\begin{array}{l}\text { Ratio of trainees } \\
\text { per active }\end{array}$} \\
\hline
\end{tabular}

Table 3: Destination of Canadian graduates by year

\begin{tabular}{lllll}
\hline & 1996 & 1997 & 1998 & 1999 \\
Canada & 8 & 14 & 7 & 4 \\
U.S.A. & 5 & 13 & 11 & 4
\end{tabular}

Table 4: Entry profile by region from 1996-2000 (July) (n=50)

\begin{tabular}{|c|c|c|c|c|c|}
\hline & Maritimes & Quebec & Ontario & Manitoba, & Alberta \\
\hline & & & & SK & $\mathrm{BC}$ \\
\hline Canadian Graduates & 6 & 12 & 14 & 2 & 6 \\
\hline $\begin{array}{l}\text { IMGs and re-entry } \\
\text { physicians }\end{array}$ & & & 2 & 3 & \\
\hline $\begin{array}{l}\text { Relocations from } \\
\text { within Canada }\end{array}$ & 1 & 1 & 1 & & 2 \\
\hline
\end{tabular}

Table 5: Predicted effect of exit from the Canadian neurosurgery workforce and current number of trainees

\begin{tabular}{|c|c|c|c|c|c|c|c|}
\hline Year & 2000 & 2001 & 2002 & 2003 & 2004 & $\ldots$ & 2009 \\
\hline Positions & 12 & 14 & 17 & 13 & 14 & $\ldots$ & 40 \\
\hline Graduates & $6^{*}$ & $6^{*}$ & $12 *$ & $8^{*}$ & 16 & $\ldots$ & 80 \\
\hline Surplus & & & & & 2 & $\ldots$ & 40 \\
\hline \multicolumn{8}{|l|}{$* 50 \%$ retention } \\
\hline Assumptions: & \multicolumn{7}{|c|}{$\begin{array}{l}\text { Age/health related retirement continues at } 4.5 / \text { year, exit } \\
\text { from emigration/other continues at } 4 / \text { year, current } \\
\text { available positions are } 12,50 \% \text { retention of trainees } \\
\text { currently at the PGY- } 4,5 \text { and } 6 \text { level on July } 1,2000\end{array}$} \\
\hline
\end{tabular}


Canada in the next few years, we could encounter a surplus of graduates looking for positions as early as the year 2002 (as many as 13 surplus surgeons with a $100 \%$ retention rate). Considering the age profile of practicing neurosurgeons in Canada and the fact that trainees traditionally practice in the region where they trained, a potential surplus of young neurosurgeons looking for work during the next five years will occur principally in Ontario and Quebec.

\section{Summary}

From January 1, 1996 to July 1, 2000 there was no change in the proportion of neurosurgeons 66 years or older but the median age of retirement crept up to age 67 . There was a reduction in the annual exit from the workforce from the traditional 12.5 per year to 8.5 per year and there was more relocation within Canada as well as more subspecialization. There has been no increase in the number of available positions in Canada and there appears little likelihood that many new positions will be created. The pool of eligible graduates for Canada has increased and will increase dramatically after 2003 because of the intent of the ABNS to deny board eligibility to trainees who commenced training in Canadian training programs after July 1, 1997. The current ABNS position will result in excess neurosurgery training capacity in Canada by as early as the year 2002 and certainly by the year 2004. If the ABNS position does not change, training programs need to examine their capacity and implement other strategies without delay to create new positions in Canada.

\section{CONCLUSION}

The foregoing contributions have identified a number of problems and issues that training in the neurosciences face. Are there any solutions? Dr. Goldsand has provided a blueprint for the structure of a modern training program. The job of the training program director has changed enormously in the past decade, from being a bit of administration added onto the chairman's duties to being a demanding part-time job in need of dedicated secretarial support. It seems clear that resident training will become even less service-oriented in the future. A common theme has been the recognition that hospitals need to acquire a new type of clinician to help operate increasingly sophisticated and demanding neuroscience clinical units. "Moon-lighters" seem to be a temporary solution, but perhaps salaried clinicians dedicated to hospital patient care, "hospitalists", are a more permanent solution. Hospitals and health authorities will need to recognize this and assume the responsibility of helping train and employ these individuals. To compensate for the reduction in clinical experience that accompanies an improved life-style during residency, trainees may increasingly seek postgraduate subspecialty fellowships, particularly in neurosurgery. The solution to the impending excess of neurosurgeons entering the workforce in the next ten years may lie with medical students. I suspect they will be too savvy to train in a difficult specialty in which they risk finding no work. The result may be a shortage of neurosurgical residents before too long, and that would be yet another reason why clinical services must break their dependency on residents in order to function.

Perhaps one way to adapt to the changes facing consultants is to stop protesting and follow the lead of resident housestaff. Maybe we should all stop working so hard, improve our lifestyles, and hire more help!

\section{ACKNOWLEDGEMENT}

The authors thank Ms. Laurie Arneson for her assistance in the preparation of this literature.

\section{REFERENCES}

1. Hugenholtz H: Neurosurgery Workforce in Canada, 1996 to 2011. Can Med Assoc J 1996; 155(1):39-48.

2. National Specialty Physician Review, Royal College of Physicians and Surgeons of Canada, Ottawa, 1988.

3. Williams P, Dominick-Pierre K, Vayda E et al. Women in medicine: practice patterns and attitudes. Can Med Assoc J 1990; 143:977984. 